\title{
ABNORMALITAS DALAM NOVEL PASUNG JIWA KARYA OKKY MADASARI
}

\author{
Rita Febriany dan U'um Qomariyah \\ Universitas Negeri Semarang \\ ritafebriany@gmail.com.dan uum@mail.unnes.ac.id
}

\begin{abstract}
Abstrak
Penelitian ini bertujuan untuk mendeskripsikan kriteria abnormalitas, faktor penyebab abnormalitas, dan cara mengatasi abnormalitas dalam novel Pasung Jiwa karya Okky Madasari. Pendekatan yang dilakukan dalam penelitian ini adalah pendekatan psikologi sastra yaitu pendekatan yang mempelajari kejiwaan manusia yang tercermin dalam perilaku yang nyata. Penelitian ini merupakan penelitian deskriptif kualitatif. Sasaran penelitian ini adalah perilaku abnormalitas tokoh utama dalam novel Pasung Jiwa karya Okky Madasari. Objek penelitian ini adalah novel Pasung Jiwa karya Okky Madasari. Teknik pengumpulan data menggunakan teknik baca dan catat. Berdasarkan hasil penelitian menunjukkan bahwa abnormalitas yang dialami tokoh utama terdiri atas perilaku yang tidak biasa, perilaku yang tidak dapat diterima sosial, persepsi yang salah terhadap kenyataan, stres personal yang signifikan, perilaku maladaptif, dan perilaku berbahaya.Faktor penyebab menurut tahap berfungsinya terdiri atas penyebab primer, penyebab yang menyiapkan, penyebab pencetus, penyebab yang menguatkan, dan sirkulasi faktor-faktor penyebab. Faktor penyebab menurut sumber asalnya terdiri atas faktor psikososial, dan faktor sosiokultural. Cara mengatasi abnormalitas tokoh utama terdiri atas psikoterapi, biomedis, dan hospitalisasi.
\end{abstract}

Kata kunci: psikologi sastra, abnormalitas, pasung jiwa

\begin{abstract}
The purpose of this research is to describe the criteria of abnormality, causes of abnormality, and how to overcome abnormality in Pasung Jiwa Novel by Okky Madasari. The approach of this research is literature psychology approach, an approach which studies psychological in real bahavior. This research is qualitative descriptive research. The objective of this research is abnormality behavior of main character in Pasung Jiwa Novel by Okky Madasari. The object of this research is Pasung Jiwa Novel by Okky Madasari. The technic of collecting data that is used in this research is read and write down technic. Based on the result of this research shows that abnormality of the main character that consists of unusual behavior, unacceptable social behavior, wrong preception in reality. Significant personal stress, maladaptive behavior, and dangerous behavior. The causes factor based on stage of functioning consists of primary cause, preparing cause, fusing cause, strengthening cause, and circulation of
\end{abstract}


causes. The causes based on the sources consist of psychosocial factor, and sociocultural facftor. The way to overcome abnormality of main character consists of psychotherapy, biomedical, and hozpitalization.

Keyword: literature psychology, abnormality, pasung jiwa.

\section{PENDAHULUAN}

Karya sastra merupakan pencerminan dari segi kehidupan manusia yang di dalamnya tersurat sikap, dan tingkah laku mengenai manusia itu sendiri, dan juga sikap manusia dengan manusia lainnya. Sastra dan psikologis adalah dua ilmu yang saling berhubungan, karena keduanya sama-sama berurusan dengan persoalan manusia sebagai makhluk individu dan makhluk sosial. Keduanya memanfaatkan landasan yang sama yaitu menjadikan pengalaman manusia sebagai bahan telaah. Oleh karena itu pendekatan psikologi dianggap penting penggunaannya dalam penelitian sastra (Endraswara dalam Minderop 2011: 2). Gejala-gejala psikologis tersebut tidak secara langsung diceritakan oleh pengarang, tetapi diceritakan melalui perwatakan tokohnya. Salah satu novel yang memuat akan segala permasalahan tersebut ialah novel Pasung Jiwa karya Okky Madasari. Pasung jiwa artinya jiwa yang terpasung, tidak memiliki kebebasan dan terkekang.

Novel Pasung Jiwa mengangkat kisah kaum transgender yang tidak pernah bisa bebas melakukan apa yang diinginkan jiwanya. Sasana merupakan tokoh utama dalam novel Pasung Jiwa, diceritakan sosok Sasana yang berperilaku menyimpang yaitu mempunyai kepribadian ganda maskulin dan feminim. Perilaku abnormal individu sangat erat hubungannya dengan kondisi sosial di sekitarnya. Oleh sebab itu, penelitian ini akan menganalisis abnormalitas dalam novel Pasung Jiwa karya Okky Madasari dengan menggunakan pendekatan psikologi abnormal.

Psikologi abnormal bersangkut-paut dengan tingkah laku abnormal. Pada hakikatnya, konsep tentang normalitas dan abnormalitas itu sangat samar-samar batasnya, sebab kebiasaan-kebiasaan dan sikap individu yang dirasakan sebagai normal oleh suatu kelompok masyarakat, dapat dianggap sebagai abnormalitas 
oleh kelompok kebudayaan lainnya. Individu yang dianggap abnormal oleh beberapa generasi sebelum kita, misalkan dianggap sebagai normal pada saat ini (Kartono 2009:2).

Pemilihan novel Pasung Jiwa karya Okky Madasari sebagai objek penelitian didasarkan pada beberapa alasan. Pertama, novel ini sangat tepat untuk masa sekarang, karena perilaku abnormal seperti transgender sedang banyak dibicarakan di masyarakat. Istilah transgender merujuk pada laki-laki yang berubah menjadi wanita, atau sebaliknya. Individu yang memiliki perilaku abnormal seperti itu, seringkali didiskriminasi dari lingkungannya. Kedua, novel ini banyak menceritakan pengakuan-pengakuan dari sosok transgender dan faktorfaktor yang membangun kepribadiannya. Dalam perkembangannya perilaku abnormal tersebut dapat diakibatkan oleh orang-orang terdekat seperti keluarga, lingkungan sosial yang tidak menguntungkan, dan pengalaman belajar yang tidak benar. Penolakan dari masyarakat yang berlebihan dapat membuat kekacauan dalam membangun kepribadiannya.

Ketiga, dalam novel Pasung Jiwa menguak ciri-ciri perilaku abnormal yang sering terlihat di masyarakat, seperti laki-laki berpenampilan wanita dan wanita berpenampilan laki-laki. Perilaku yang menyimpang dari norma masyarakat di tempat tersebut dapat diartikan sebagai perilaku abnormal. Berdasarkan latar belakang tersebut, tujuan penelitian ini adalah mendeskripsikan abnormalitas tokoh utama dalam novel Pasung Jiwa karya Okky Madasari, mendeskripsikan faktor penyebab abnormalitas tokoh utama dalam novel Pasung Jiwa karya Okky Madasari, dan menjelaskan cara mengatasi abnormalitas tokoh utama dalam novel Pasung Jiwa karya Okky Madasari.

Tujuan penelitian ini yaitu, mendeskripsikan abnormalitas tokoh utama dalam novel Pasung Jiwa karya Okky Madasari, mendeskripsikan faktor-faktor penyebab abnormalitas tokoh utama dalam novel Pasung Jiwa karya Okky Madasari, dan menjelaskan cara mengatasi abnormalitas tokoh utama dalam novel Pasung Jiwa karya Okky Madasari.

Selanjutnya, sebagai daya dukung dan data rekam jejak, beberapa penelitian yang terkait pernah dilakukan oleh Sanzida (2010), Wulandari (2013), 
Setyaningrum (2014), Wardani (2014), Abdullah, Sabitha (2015), Hidayah (2015). Selain kajian pustaka, teori juga dibutuhkan untuk mendukung penelitian ini. Teori yang digunakan dalam penelitian ini, yaitu (1) hakikat perilaku yang meliputi kriteria pribadi normal dan pengertian perilaku abnormal, (2) hakikat abnormalitas yang meliputi pengertian, kriteria, faktor pendorong, dan cara mengatasi perilaku abnormal, (3) pendekatan psikologi sastra.

\section{METODOLOGI PENELITIAN}

Penelitian ini menggunakan pendekataan psikologi sastra yaitu pendekatan yang mempelajari kejiwaan manusia yang tercermin dalam perilaku yang nyata. Penelitian ini difokuskan tentang abnormalitas yang dialami tokoh utama baik secara fisik maupun secara psikologis.

Analisis tentang abnormalitas bahwa perilaku abnormal adalah kondisi emosional seperti kecemasan dan depresi yang tidak sesuai dengan situasinya (S.Nevid, Rathus, dan Greene 2002:5). Untuk menentukan abnormalitas perlu adanya beberapa kriteria yaitu, perilaku yang tidak biasa, perilaku yang tidak dapat diterima secara sosial atau melanggar norma sosial, persepsi atau interpretasi yang salah terhadap realitas, berada dalam stres personal yang signifikan, perilaku maladaptif, dan perilaku berbahaya.

Data yang dijadikan objek dalam penelitian ini adalah penggalan wacana yang menunjukkan abnormalitas tokoh utama dalam novel Pasung Jiwa karya Okky Madasari. Sumber data dalam penelitian ini adalah novel Pasung Jiwa karya Okky Madasari. Novel ini diterbitkan oleh PT Gramedia Pustaka Utama; Jakarta pada tahun 2013 cetakan pertama dengan tebal $20 \mathrm{~cm}$ dan 328 halaman. Sumber data lain yang dapat mendukung adalah buku teori dan buku acuan lain yang digunakan peneliti untuk mendukung jalannya penelitian, yaitu buku tentang teori psikologi sastra, psikologi abnormal, dan buku-buku lain yang mendukung penelitian ini.

Teknik pengumpulan data yang digunakan adalah teknik baca catat yaitu membaca dan memahami seluruh jalan cerita novel Pasung Jiwa karya Okky Madasari, kemudian mencatat hal-hal yang berkaitan dengan masalah yang akan 
diteliti. Pengumpulan data dalam penelitian ini yaitu dengan mencari kriteria abnormalitas, faktor-faktor penyebab terjadinya abnormalitas yaitu faktor penyebab berdasarkan tahap berfungsinya dan menurut sumber asalnya, dan cara mengatasi abnormalitas tokoh utama. Hasil analisis dideskripsikan berdasarkan data-data yang terkumpul, baik berupa kata, kalimat maupun paragraf yang terdapat dalam sumber data yakni pada novel Pasung Jiwa karya Okky Madasari.

Proses analisis data yang dimaksudkan adalah untuk mempermudah cara kerja peneliti dalam memperoleh data. Adapun langkah-langkah yang dilakukan dalam analisis data sebagai berikut: (1) identifikasi data yang sesuai dengan rumusan masalah, (2) data dikumpulkan sesuai dengan tujuan penelitian, (3) data yang sudah siap diinterpretasikan dengan memberikan makna, mendeskripsikan hasil analisi, (5) menarik kesimpulan dan mengujinya.

\section{HASIL PENELITIAN DAN PEMBAHASAN}

Hasil penelitian tentang abnormalitas tokoh utama dalam novel Pasung Jiwa karya Okky Madasari disajikan dalam tiga bagian permasalahan, meliputi: (1) Kriteria perilaku abnormal tokoh utama dalam novel Pasung Jiwa karya Okky Madasari, (2) Faktor penyebab abnormalitas tokoh utama dalam novel Pasung Jiwa karya Okky Madasari, (3) Cara mengatasi abnormalitas tokoh utama dalam novel Pasung Jiwa karya Okky Madasari.Hasil penelitian berupa data deskriptif yaitu kutipan pada novel beserta penjelasannya.

\section{1) Abnormalitas Tokoh Utama dalam Novel Pasung Jiwa Karya Okky Madasari}

1. Perilaku yang luar biasa, tidak lazim, atau secara harfiah yang menyimpang dari norma. Kriteria ini cocok diterapkan untuk sifat-sifat kepribadian tertentu, seperti jenius, dan idiot.

Saat masuk sekolah dasar, aku sudah mahir memainkan komposisi-komposisi klasik dunia. Beethoven, Chopin, Mozart, Back, Brahms. Sebut saja! Aku bisa memainkan semua dengan indah (Pasung Jiwa, 2013:15). 
Sasana yang sudah mahir memainkan musik piano sejak masuk Sekolah Dasar dapat dikatakan bahwa Sasana termasuk anak yang menyimpang karena perilakunya berbeda jauh dari perilaku rata-rata anak seusianya. Jenius yang dialami Sasana adalah sifat ekstrem yang mempunyai nilai positif.

2. Perilaku yang tidak dapat diterima secara sosial atau melanggar norma sosial.

Sekolah gempar.Aku jadi bahan omongan hampir semua guru. Seluruh teman sekelas mencibir dan menyindirku, aku dianggap aneh dan punya kelainan hanya gara-gara menggambar seorang perempuan tanpa baju saat pelajaran kesenian (Pasung Jiwa, 2013:28).

Sasana dianggap menyimpang dari norma sosialnya karena gambarnya tidak wajar digambar oleh anak seusianya, berbeda jika laki-laki yang berusia 30 tahun yang menggambar wanita telanjang masih dapat dikatakan hal yang wajar.

3. Persepsi atau interpretasi yang salah terhadap realita. Melihat sesuatu ataupun mendengar suara tidak ada objeknya akan disebut sebagai halusinasi, di mana di dalam budaya kita sering diangap sebagai tandatanda yang mendasari suatu gangguan.

Aku ketakutan. Aku sedang tidak aman. Segala hal bisa mereka lakukan. Termasuk menyekapku dan menelanjangiku, lalu menyuruhku melayani nafsu mereka.

Tidak! Hal seperti itu tidak boleh aku alami lagi. Aku harus menyelamatkan diriku sekarang. Aku harus mengamankan diri sambil mencari pertolongan. Tolong...tolong...tolong...! teriakku sambil berlari (Pasung Jiwa, 2013:109).

Terjadinya halusinasi dapat dikarenakan seseorang yang sedang depresi atau stres berat. Sasana mengalami halusinasi melihat orang-orang yang 
ada di kampus seperti pada saat anggota TNI melecehkannya di dalam sel.

4. Berada dalam stres personal yang signifikan. Kondisi stres personal yang diakibatkan oleh gangguan emosi, seperti kecemasan, ketakutan, dan depresi dapat dianggap abnormal.

Hanya satu jam guru itu mengajariku. Tapi rasanya sangat lama. Aku tak menyukainya. Bunyi piano tak lagi indah menyapa telingaku. Ia kini telah menjelma jadi bunyi-bunyian yang mengganggu, yang membuatku merasa dikejar-kejar atau terkurung dalam ruangan (Pasung Jiwa, 2013:14).

Sasana mengalami gangguan kecemasan terbukti ketika ia merasa dikejar-kejar bunyi piano, sedangkan Sasana diceritakan sebelumnya adalah anak yang pandai bermain piano. Pada kondisi normal hal itu bukanlah suatu kewajaran.

5. Perilaku maladaptif atau self-defeating

Perilaku yang tidak menghasilkan kebahagiaan dan bukan self-fulfillment dapat dianggap sebagai abnormal.

Hidupku kini hanya untuk berdendang dan bergoyang. Sudah tak terhitung berapa kali aku membolos kuliah. Aku malah sudah lupa bahwa aku berada di kota ini untuk kuliah. Kiriman orangtua tetap datang tiap bulan (Pasung Jiwa, 2013:49).

Perilaku seperti itu dapat dikatakan sebagai perilaku yang maladaptif karena Sasana lebih memilih hal yang tidak diharapkan semua orang. Pada kondisi normal hal yang wajar dilakukan adalah melanjutkan kuliahnya dan mencari pekerjaan yang lebih layak, sebaliknya Sasana lebih memilih menjadi biduan dangdut di jalanan.

6. Perilaku yang menimbulkan bahaya bagi orang itu sendiri ataupun orang lain dapat dikatakan abnormal. Dalam hal ini konteks sosial menjadi masalah penting. 
Bisa jadi aku akan menghabiskan sisa umurku di penjara. Bisa jadi aku baru keluar setelah tua dan tak lagi bisa melakukan apa-apa. Atau mungkin saja aku hanya perlu hidup setahun dua tahun di dalam penjara. Tapi apa yang akan kulakukan sesudahnya? apalah arti Sasa jika tak lagi bisa menyanyi dan bergoyang sesukanya? Jadi buat apa aku menunda kematian hanya untuk kesia-sian? (Pasung Jiwa, 2013:305).

Sasana berpikir tidak ada lagi orang yang bisa menolongnya keluar dari permasalahan hidupnya ini, ia menjadi putus asa dan ingin mengakhiri hidupnya. Sasana berpikir bunuh diri adalah cara satu-satunya agar ia mendapat kebebasan yang sesungguhnya.

\section{2) a. Faktor Penyebab Perilaku Abnormal Tokoh Utama dalam Novel Pasung Jiwa Karya Okky MadasariMenurut Tahap Berfungsinya}

1. Penyebab primer.Kondisi yang harus dipenuhi agar sesuatu gangguan dapat muncul, meskipun dalam kenyataannya gangguan tersebut tidak atau belum muncul.

Perasaanku padanya selalu campur antara iri dan sayang. Rasa iri yang sudah kupendam sejak kecil ternyata tak bisa hilang setelah aku dewasa. Melihat Melati saat ini, rasa iriku semakin memuncak (Pasung Jiwa, 2013:105).

Perasaan iri yang dimiliki Sasana sejak kecil membuat ia melakukan hal-hal yang tidak normal seperti berpakaian seperti adiknya dan suka berdandan layaknya perempuan.

2. Penyebab yang menyiapkan.Penyebab yang menyiapkan adalah kondisi yang mendahului dan membuka jalan bagi kemungkinan terjadinya gangguan tertentu dalam kondisi-kondisi tertentu di masa mendatang.

Apa yang harus kulakukan? Tak ada.Aku laki-laki kecil tak berdaya, yang hanya bisa melakukan setiap hal yang 
orangtuaku tunjukkan. Aku terus memainkan piano itu (Pasung Jiwa, 2013:14)

Sasana menuruti kemauan orangtuanya untuk bermain musik piano. Sasana tidak benar-benar menyukainya, ia hanya membuat orangtuanya bangga dan bahagia

3. Penyebab pencetus.Penyebab pencetus adalah setiap kondisi yang tidak tertahankan bagi individu dan mencetuskan gangguan.

Melati.Aku suka mengucapkannya berulang kali. Berbeda sekali dengan namaku: Sasana, sama sekali tak indah. Terlalu garang, terlalu keras. Selalu mengingatkanku pada perkelahian dan darah, seperti tempat orang bertinju. Tetapi ibuku selalu meyakinkan bukan itu arti namaku.Sasana bagi dia adalah kejantanan, keberanian, keperkasaan (Pasung Jiwa, 2013: 16).

Sasana sudah memunculkan sisi-sisi feminimnya. Seperti halnya perempuan, iatidak menyukai perkelahian, darah, dan kekerasan. Kekecewaan terhadap namanya sendiri ia ungkapan dengan membandingkannya dengan nama adiknya yaitu Melati.

4. Penyebab yang menguatkan. Kondisi yang cenderung mempertahankan atau memperteguh tingkah laku maladaptif yang sudah terjadi.

Melihat Melati saat ini, rasa iriku semakin memuncak. Begitu cerianya dia dengan baju-baju cantik yang ia kenakan. Begitu indah parasnya dengan pulasan bedak tipis dan pelembab bibir yang tak berwarna. Dalam hati nanti aku akan mencoba dandan seperti Melati saja (Pasung Jiwa, 2013:106).

Ketertarikannya tentang perempuan semenjak kecil membuat Sasana selalu ingin mengetahui hal-hal yang berkaitan dengan perempuan. Hal tersebut dapat dikatakan sebagai hal yang menguatkan perilaku abnormal Sasana. 
5. Sirkulasi faktor-faktor penyebab.Dalam kenyataan, suatu gangguan perilaku jarang disebabkan oleh satu penyebab tunggal.Serangkaian faktor penyebab yang kompleks.

Bagiku setiap ruas tubuh Melati adalah keindahan, karya seni, sesuatu yang harus dikagumi dan membuat iri (Pasung Jiwa, 2013:28).

Sepertinya memang sudah jodohku bertemu Cak Jek. Kami berkenalan di warung kopi yang ada di dekat kosaku. Awalnya kami hanya ngobrol-ngobrol (Pasung Jiwa, 2013:47).

Sambil terus tersenyum, Cak Jek mengeluarkan satu per satu isi plastik itu: sepatu merah dengan hak tinggi dan lancip, rok-rok mini dan blus-blus seksi warna-warni. Waah... benda-benda yang indah (Pasung Jiwa, 2013:52).

Penyebab awal mula ketidakwajaran dalam diri Sasana ketika ia merasa iri dengan segala keindahan yang dimiliki adiknya itu. Berjalannya waktu hasrat tidak wajar itu tersalurkan ketika Sasana bertemu Cak Jek di Malang. Cak Jek telah mengubah Sasana menjadi Sasa sang biduan dangdut yang punya goyangan maut, ketika itu Sasana seperti menemukan tempat jiwanya yang sebenarnya.

\section{3) b Faktor Penyebab Perilaku Abnormal Tokoh Utama dalam Novel Pasung Jiwa Karya Okky Madasari Menurut Sumber Asalnya.}

1. Faktor biologis

Keadaan biologis atau jasmani yang dapat menghambat perkembangan maupun fungsi sang pribadi dalam kehidupan sehari-hari, seperti kelainan gen, kurang gizi, penyakit, dan sebagainya. 
2. Faktor psikososial

Perilaku abnormal yang diakibatkan oleh keadaan psikologis dan pengaruh dari lingkungan sosial selama masa perkembangan individu.

Mereka selalu terlihat tertawa dan bahagia setiap aku bisa memencet dan membunyikannya. Aku melakukannya setiap hari, jangan-jangan juga sepanjang hari. Tak ada lagi yang bisa kuingat dari masa kecilku selain piano itu (Pasung Jiwa 2013:14).

Keegoisan orangtua sudah terlihat semenjak Sasana masih kecil. Orangtuanya selalu berfikir bahwa hal yang menurut mereka baik akan baik juga untuk anaknya. Keadaan tersebut membuat anak terbebani. Kurangnya ruang lingkup dari orangtua membuat Sasana semenjak masih kecil hanya bermain dengan piano, tidak ada kenangan-kenangan yang masih ia ingat kecuali memainkan piano.

3. Faktor sosio-kultural

Faktor-faktor sosiokultural meliputi keadaan objektif dalam masyarakat atau tuntutan dari masyarakat yang dapat berakibat menimbulkan tekanan pada individu dan selanjutnya melahirkan berbagai bentuk gangguan.

Apa yang salah dengan pakaianku? Apa yang salah dengan penampilanku? Ini caraku untuk membuat orang lain terhibur dan senang. Aku pun senang berdandan dan berpakaian seperti ini. Jadi apa salahnya? Seenaknya saja bilang aku bisa dipakai orang. Cih! (Pasung Jiwa, 2013: 98).

Masyarakat menganggap laki-laki yang berpakaian wanita termasuk perilaku yang menyimpang karena menyalahi kodrat lahirnya. Keadaan tersebut membuat orang yang berpenampilan seperti Sasana kerap sekali 
direndahkan dan bahkan disakiti, alasannya adalah masyarakat belum bisa menerima kondisi seseorang yang seperti itu.

\section{3) Cara mengatasi sikap abnormal tokoh utama dalam novel Pasung Jiwa karya Okky Madasari}

1. Psikoterapi

a. Terapi Humanistik. Terapi humanistik berfokus pada pengalaman pasien yang subjektif dan disadari. Terapi humanistik juga berfokus pada apa yang dialami klien saat ini dan sekarang daripada pengalaman masa lalu.

Ia mengulurkan tangan sambil menyebutkan nama. Senyumnya manis sekali. Aku menerima uluran tangan itu.Kami berjabat tangan. Tanda kesetaraan., simbol kesederajatan. Yang waras dan tak waras kini tak lagi dipisahkan oleh dua lapisan kasta (Pasung Jiwa, 2013: 131).

Di rumah sakit jiwa inilah Sasana mendapatkan tempat yang mau menerima semua keluh kesahnya. Mengerti keadaannya dan satu-satunya orang yang percaya akan kewarasan Sasana. Orang ini bernama Masita, seorang psikiatri di rumah sakit jiwa tempat Sasana dirawat.

b. Terapi kognitif. Terapis kognitif mendorong klien untuk mengenali dan mengubah kesalahan dalam berfikir.

Masita pun menjagaku dengan cara tidak waras. Ia meninggalkan wilayah warasnya untuk bertemu denganku di simpangan ketidakwarasan. Padanya aku ceritakan semua kegelisahanku (Pasung Jiwa, 2013:143)

Masita sebagai seorang terapis memberikan pengertian kepada Sasana bahwa tidak ada perbedaan antara dia dan orang-orang di sekitarnya. Hanya saja cara pandang dan persepsi mereka salah mengenai Sasana. 
c. Terapi keluarga. Keluarga menjadi unit penanganan utama. Terapi keluargaditujukan untuk membantu keluarga yang bermasalah dalam memecahkan konflik.

Ibu selalu ada di sebelahku saat aku terbangun.Kenapa sering sekali terjadi adegan seperti ini dalam hidupku?Terbangun dalam keadaan lemah dan tanpa berenergi, dan ibu ada di sampingku dengan wajahnya yang sendu (Pasung Jiwa, 2013: 127).

Ibu Sasana menempatkan dirinyasebagai seorang teman yang senantiasa memperhatikan Sasana.

2. Biomedis. Terapi biomedis meliputi terapiobat dan evaluasi pendekatan bilogis.

Aku terbangun dalam kamar berteralis. Entah bagaimana aku bisa sampai di tempat ini. Yang terakhir kuingat. Aku meronta-ronta saat mereka menyuruhku keluar dari mobil. Aku tak tahu lagi apa yang terjadi sesudahnya. Tapi saat itu aku merasakan nyeri tertusuk jarum di lenganku. Itu pasti bius. Aku dibuat tak sadar agar bisa dibawa ke tempat ini(Pasung Jiwa, 2013:111).

Dalam hal ini, terapi biomedis dilakukan ketika Sasana tidak patuh mengendalikan dirinya.

3. Hospitalisasi. Hospitalisasi merupakan istilah untuk perawatan rumah sakit bagi pasien yang mengalami gangguan psikologis.

Perawat-perawat yang bertugas mendekatiku. Mereka seperti ingin memastikan apa yang sedang terjadi padaku, apakah aku baik-baik saja. "Sasana, ini pakai baju siapa?" seorang perawat perempuan bertanya dengan lembut. "Baju saya sendiri”, jawabku sambil tersenyum. "Sasana, ini pakaian perempuan. Bukan 
pakaian kamu. Ganti baju lagi ya dengan piama yang biasa”, ujarnya sambil menggandeng tanganku, menuntunku untuk meninggalkan kerumunan orang-orang (Pasung Jiwa, 2013:123).

Sasana dibiasakan untuk melakukan kegiatan sehari-hari, seperti senam, makan dan mandi sendiri. Hal itu diberikan agar suatu ketika jika diminta oleh keluarga kembali, ia dapat melakukan pekerjannya sendiri.

\section{KESIMPULAN DAN SARAN}

Berdasarkan pembahasan pada bab sebelumnya, simpulan yang dapat dikemukakan adalah sebagai berikut.

1) Abnormalitas yang dialami tokoh utama dalam novel Pasung Jiwa karya Okky Madasari yang terdapat dalam penelitian ini meliputi: perilaku yang tidak biasa, perilaku yang tidak dapat diterima secara sosial atau melanggar norma sosial, persepsi atau interpretasi yang salah terhadap realita, berada dalam stres personal yang signifikan, perilaku maladaptif atau self-defeating, dan perilaku berbahaya seperti niatan ingin mengakhiri hidupnya.

2) Faktor penyebab abnormalitas tokoh utama dalam novel Pasung Jiwa karya Okky Madasari. Berdasarkan tahap berfungsinya yaitu penyebab primer, penyebab yang menyiapkan, penyebab pencetus, penyebab yang menguatkan, dan sirkulasi faktor-faktor penyebab. Berdasarkan sumber asalnya yaitu psikososial dan sosio-kultural.

3) Cara mengatasi abnormalitas tokoh utama dalam novel Pasung Jiwa karya Okky Madasari. Psikoterapi dibagi menjadi 3 yaitu terapi humanistik, terapi kognitif, dan terapi keluarga. Biomedis dan hospitalisasi. 
Berdasarkan simpulan hasil penelitian yang telah dikemukakan tersebut, saran yang dapat diberikan adalah sebagai berikut.

1) Abnormalitas dapat dikenali dengan beberapa kriteria yang sudah dibahas pada bab sebelumnya, dengan mengenali perilaku abnormal kita dapat memahami kondisi individu tersebut dan belajar saling menerima satu sama lain.

2) Mengetahui faktor-faktor penyebab abnormalitas dapat menjadi pelajaran yang berharga dalam kehidupan sehari-hari dan bermasyarakat supaya tetap memiliki kepedulian yang tinggi terhadap sesama anggota masyarakat.

3) Hasil penelitian ini diharapkan dapat dimanfaatkan oleh penelitian selanjutnya sebagai referensi dan pengetahuan tentang abnormalitas, khususnya kriteria, faktor penyebab, dan cara mengatasi abnormalitas.

\section{Daftar Pustaka}

Abdullah, Aida, dan Sabitha Marican. 2015. The Efect of Big Five Personality Traits on Deviant Behavior. Procedia.

Hidayah, N.W. 2015. "Problem Kejiwaan Tokoh Utama dalam Novel Pasung Jiwa Karya Okky Madasari”. Skripsi. Universitas Negeri Yogyakarta.

Kartono, Kartini. 2009. Psikologi Abnormal dan Abnormalitas Seksual. Bandung: Mandar Maju.

Madasari, Okky. 2013. Pasung Jiwa. Jakarta: PT Gramedia Pustaka Utama.

Minderop, Albertine. 2011. Psikologi Sastra. Jakarta: Yayasan Pustaka Obor Indonesia

Nevid, J. S., Rathus, S. A.,Greene, B. Edisi Kelima. Jilid 1. 2002. Psikologi Abnormal. Jakarta: Erlangga.

Setyaningrum, P.A. 2014. "Abnormalitas Seksual Tokoh dalam Kumpulan Cerpen Cerita Pendek Tentang Cerita Cinta Pendek karya Djenar Maesa Ayu”. Skripsi. Universitas Negeri Yogyakarta.

Supratiknya, A. 1995. Mengenal Perilaku Abnormal. Yogyakarta:Kanisius.

Wardhani, Yuanita Kusuma. 2014. "Trauma Kejiwaan Tokoh Utama Novel Dream Karya Joannes Rhino". Skripsi. Universitas Negeri Yogyakarta.

Wohab, Md. Abdul, dan Sanzita Akhter. 2010. The Effects of Childhood Sexual Abuse on Children's Psychology and Employment. Procedia.

Wulandari, D.A. 2013. "Abnormalitas dalam Novel Halo, Aku dalam Novel Karya Nuril Basri Kajian Psikologi Sastra”. Skripsi. Universitas Negeri Diponegoro. 